\title{
Solute-specific scaling of inorganic nitrogen and phosphorus uptake in streams
}

\author{
R. O. Hall Jr. ${ }^{1}$, M. A. Baker ${ }^{2}$, E. J. Rosi-Marshall ${ }^{3}$, J. L. Tank ${ }^{4}$, and J. D. Newbold ${ }^{5}$ \\ ${ }^{1}$ Department of Zoology and Physiology, University of Wyoming, Laramie, Wyoming, 82071, USA \\ ${ }^{2}$ Department of Biology and Ecology Center, Utah State University, Logan, Utah, 84322, USA \\ ${ }^{3}$ Cary Institute of Ecosystem Studies, Box AB, Millbrook, New York, 12545, USA \\ ${ }^{4}$ Department of Biological Sciences, University of Notre Dame, Notre Dame, Indiana, 46556, USA \\ ${ }^{5}$ Stroud Water Research Center, 970 Spencer Road, Avondale, Pennsylvania, 19311, USA
}

Correspondence to: R. O. Hall Jr. (bhall@uwyo.edu)

Received: 4 April 2013 - Published in Biogeosciences Discuss.: 10 April 2013

Revised: 2 October 2013 - Accepted: 11 October 2013 - Published: 15 November 2013

\begin{abstract}
Stream ecosystem processes such as nutrient cycling may vary with stream position in the network. Using a scaling approach, we examined the relationship between stream size and nutrient uptake length, which represents the mean distance that a dissolved solute travels prior to removal from the water column. Ammonium $\left(\mathrm{NH}_{4}^{+}\right)$uptake length increased proportionally with stream size measured as specific discharge (discharge/stream width) with a scaling exponent $=1.01$. In contrast, uptake lengths for nitrate $\left(\mathrm{NO}_{3}^{-}\right)$and soluble reactive phosphorus (SRP) increased more rapidly than increases in specific discharge (scaling exponents $=1.19$ for $\mathrm{NO}_{3}^{-}$and 1.35 for SRP). Additionally, the ratio of inorganic nitrogen $(\mathrm{N})$ uptake length to SRP uptake length declined with stream size; there was relatively lower demand for SRP compared to $\mathrm{N}$ as stream size increased. Finally, we related the scaling of uptake length with specific discharge to that of stream length using Hack's law and downstream hydraulic geometry. Ammonium uptake length increased less than proportionally with distance from the headwaters, suggesting a strong role for larger streams and rivers in regulating nutrient transport.
\end{abstract}

\section{Introduction}

One of the most elegant applications of the ecosystem concept (O'Neill, 2001) has been to define the boundary or edge of an ecosystem and quantify the functioning (e.g., material cycling or energy flow) within this spatially explicit unit, as did Bormann and Likens (1967) for a small watershed. When ecosystems are well bounded (Post et al., 2007), we predict that as they change size, attributes will change concurrently. For example, dissolved solute concentrations in streams varied with the size of the drainage basin (Likens and Buso, 2006). Further, position in a watershed can determine chemical attributes of lakes (Kratz et al., 1997; Soranno et al., 1999). Despite previous recognition of these patterns, there are few quantitative relationships linking ecosystem processes and, for example, position in a drainage network (Ensign and Doyle, 2006). Here we use an allometric scaling approach applied to stream ecosystems to examine how nutrient uptake in streams varies as a function of ecosystem size measured as specific discharge and position in the network.

Streams and rivers are well bounded laterally by their banks, but are open longitudinally, and because of this property, ecologists have developed a scale-independent means of measuring nutrient cycling. Uptake length is the average distance a nutrient molecule travels before being removed from the water column via biotic processes (Newbold et al., 1981; Webster and Patten, 1979), and is estimated from the inverse of a first-order uptake rate of nutrients experimentally added to the water column of a stream, either as a tracer (Newbold et al., 1981), or as a small increment to ambient concentration (Stream Solute Workshop, 1990). The uptake length metric is scale independent in the sense that the length of stream chosen should not influence the value of the measured uptake length; however, stream discharge and width will strongly regulate how far nutrients travel (Tank et al., 2008). The 
nutrient-spiraling approach combines both hydrologic and biological controls on nutrient uptake in flowing waters, and also quantifies the degree to which upstream reaches are functionally linked to downstream reaches or other ecosystem types (e.g., a lake; Arp and Baker, 2007). For example, if streams and rivers have short uptake lengths, on the order of 10-100 s of meters, then nutrient transport downstream may be mitigated (Mulholland et al., 2008). The role of small streams in taking up dissolved nutrients has been well studied, with $>970$ nutrient uptake experiments reported thus far (Ensign and Doyle, 2006; Tank et al., 2008). We emphasize that the effect of nutrient uptake on downstream transport depends on the subsequent fate of the nutrient. For example, uptake may be balanced by mineralization, leaving transport unaffected; it may alter the timing of transport through fluctuations in benthic biomass and floodplain storage; it may alter the form and hence biological availability of nutrients in transport; and, in the case of denitrification, it may reduce downstream transport by releasing nitrogen permanently into the atmosphere.

Nearly all nutrient uptake experiments have been conducted in small streams (Tank et al., 2008). Considering how nutrient uptake scales with stream discharge allows an initial evaluation of the degree to which large streams and rivers remove nutrients from the water column. Given a lack of empirical data, researchers have conservatively assumed that nutrient demand is constant throughout a river network (Wollheim et al., 2006). Using a meta-analysis of previously published data, here we examine how nutrient uptake scales with stream-specific discharge to both test the assumption of constancy by Wollheim et al. (2006) and to begin to predict how larger lotic ecosystems might function. We use a scaling approach whereby we relate uptake length with specific discharge, i.e., discharge per unit stream width. An isometric relationship (i.e., scaling exponent $=1$ ) indicates constant nutrient demand as assumed by Wollheim et al. (2006), whereas a slope < or > 1 indicates an allometric relationship, and thus nutrient demand changes with specific discharge.

Although there are many data on how streams cycle either inorganic nitrogen $(\mathrm{N})$ or phosphorus $(\mathrm{P})$, fewer studies examine how these elements cycle together. Cross et al. (2005) posited that elemental concentrations of benthic organisms will drive uptake of $\mathrm{N}$ relative to $\mathrm{P}$, and if elemental composition were to change then it would alter the ratio of $\mathrm{N}$ vs. $\mathrm{P}$ uptake, but this has not been widely tested. Also, while the processes that control inorganic $\mathrm{N}$ uptake are mainly biotic and include a combination of assimilatory and dissimilatory processes, those that control inorganic $\mathrm{P}$ uptake have an additional abiotic component driven by sorption/desorption processes with a significant role of suspended particles. Therefore, we hypothesized that $\mathrm{N}$ and $\mathrm{P}$ uptake could be decoupled, and as such the stoichiometry of nutrient demand may vary along a river network.

Here we compare the demand for inorganic $\mathrm{N}$ (as ammonium $\mathrm{NH}_{4}^{+}$and nitrate $\mathrm{NO}_{3}^{-}$) and inorganic $\mathrm{P}$ (as soluble re- active phosphorus SRP) by scaling nutrient uptake length as a function of specific discharge using previously published data on nutrient uptake. Given these scaling relationships between specific discharge and nutrient uptake length, we use scaling rules from fluvial geomorphology and hydrology (Dodds and Rothman, 2000; Leopold and Maddock, 1953; Rigon et al., 1996) to predict how nutrient uptake length changes along a river continuum.

\section{Methods}

\subsection{Scaling nutrient uptake length from existing studies}

We first relate uptake length, $S_{\mathrm{w}}$, with specific discharge, $Q / w$, where $Q$ is stream discharge $\left(\mathrm{m}^{3} \mathrm{~min}^{-1}\right)$ and $w$ is average wetted stream width $(\mathrm{m})$. We choose this metric because it enables the calculation of uptake velocity $v_{\mathrm{f}}$ $\left(\mathrm{m} \mathrm{min}^{-1}\right)$, a stream size-independent measure of nutrient demand (Stream Solute Workshop, 1990), which can be interpreted as demand relative to nutrient concentration, and is calculated as:

$v_{\mathrm{f}}=\frac{Q / w}{S_{\mathrm{w}}}$.

We then test how specific discharge relates to nutrient uptake by scaling uptake length as a function of specific discharge. Rearranging Eq. (1),

$S_{\mathrm{w}}=\frac{Q / w}{v_{\mathrm{f}}}$

suggests that $S_{\mathrm{w}}$ will increase as $Q / w$ increases, while $S_{\mathrm{w}}$ will decrease with higher biological or chemical demand $\left(v_{\mathrm{f}}\right)$. Thus we propose a null model where constant $v_{\mathrm{f}}$ along a gradient of increasing $Q / w$ will result in a scaling prediction of $S_{\mathrm{w}} \propto\left(\frac{Q}{w}\right)^{a}$, where $a=1$. In other words, given constant biological demand relative to concentration (measured as $v_{\mathrm{f}}$ ) across a range of $Q / w, S_{\mathrm{w}}$ should increase at the same rate as $Q / w$ and have a scaling exponent of 1 . Using a metaanalysis of nutrient uptake experiments, we tested if scaling exponents differed from 1 for each of the 3 inorganic solutes $\mathrm{NH}_{4}^{+}, \mathrm{NO}_{3}^{-}$, and SRP.

We gathered literature data on nutrient uptake and ambient nutrient concentrations in streams from recent reviews on nutrient spiraling in streams and rivers (Ensign and Doyle, 2006; Tank et al., 2008) plus other studies published after these two meta-analyses (Supplement). In addition, we used unpublished data from a stream in Idaho (B. J. Koch, unpublished data), a stream in Venezuela (A. S. Flecker et al., unpublished data), one in Yellowstone National Park (Tronstad et al., unpublished data), several streams in New Zealand (J. L., Tank, unpublished data), and an urban stream in Laramie, WY, (R. O. Hall, unpublished data) for a total of 969 separate nutrient uptake experiments. We included streams that 
authors identified as being located in areas of intense human activity, such as streams draining agricultural and urban catchments, but we analyzed these data separately from less altered streams. Most streams in the data set were relatively small, reflecting the predominance of research carried out in headwater streams; $90 \%$ of streams in this data set had discharge between 0.002 and $0.7 \mathrm{~m}^{3} \mathrm{~s}^{-1}$, with a median of $0.035 \mathrm{~m}^{3} \mathrm{~s}^{-1}$. When individual streams included multiple measurements, using R package plyr (Wickham, 2011) we averaged $Q / w$ and $S_{\mathrm{w}}$ to avoid bias toward streams with multiple measurements. Our data set includes nutrient additions using three different solutes, $\mathrm{NH}_{4}^{+}, \mathrm{NO}_{3}^{-}$, and SRP, though all three were not often measured in a single ecosystem.

For the scaling regressions we calculated slopes and their $95 \%$ confidence intervals using standardized major axis (SMA) regression package (S)MATR in R (R Development Core Team, 2011); SMA regression minimizes variation in both $x$ and $y$ variables and thus better describes their relationship when the value of the slope is of biological interest in a symmetrical relationship (Warton et al., 2006). We also tested how scaling relationships differed between lessaltered (i.e., reference) and human-altered streams by testing if they shared a common slope and intercept (Warton et al., 2006). These tests are analogous to an SMA analysis of covariance, but with different estimation procedures. A slope difference is estimated based on a likelihood ratio test that groups share a common slope; differences in intercept are estimated by comparing a Wald statistic to a chi-square distribution (Warton et al., 2006). To include the effect of concentration in controlling variation in uptake length, we used multiple linear regression following Hall et al. (2009b). Because of the difference in line fitting between SMA and multiple linear regression, we recognize that the parameter estimates are not directly comparable, but our primary purpose is to test the extent to which nutrient concentration contributed to variation in $S_{\mathrm{w}}$.

\subsection{Scaling nutrient uptake with stream length}

Using the scaling coefficients calculated for $\mathrm{NH}_{4}^{+}, \mathrm{NO}_{3}^{-}$, and SRP, we then estimate how uptake length will scale downstream from headwaters to a larger river along a river continuum (Vannote et al., 1980). We use stream length to define position in the network so that we can compare metrics having the same unit of length. As previously hypothesized, nutrient uptake length $\left(S_{\mathrm{w}}\right)$ will scale as a function of specific discharge $(Q / w)$ as

$S_{\mathrm{w}} \propto\left(\frac{Q}{w}\right)^{a}$,

where $a$ is the scaling exponent measured in the above analysis. We relate stream width to discharge based on the powerlaw representation of stream hydraulic geometry:

$w \propto Q^{b}$
Combining Eq. (3) and Eq. (4), uptake length relates with $Q$ as

$Q \propto S_{\mathrm{w}} \frac{1}{(1-b) a}$.

Next we scaled discharge as a function of stream length from the headwaters. Hack's law states that the length of a stream from headwaters to the end of a watershed $(L)$ will scale with drainage area $(A)$ as

$L \propto A^{h}$.

It has typically been assumed that discharge $(Q)$ scales with watershed area isometrically, but empirical work has demonstrated that

$Q \propto A^{c}$

(Galster, 2007). Substituting $Q^{1 / c}$ for $A$ and solving gives:

$L^{\frac{c}{h}} \propto Q$.

Combining Eq. (5) and Eq. (8) and solving for $S_{\mathrm{w}}$ gives

$S_{\mathrm{W}} \propto L^{\frac{(1-b) a c}{h}}$

The variables $a, b, c$, and $h$ are not known with certainty, therefore we used a Monte Carlo approach to evaluate the expression

$m=\frac{(1-b) a c}{h}$.

We assume that the parameter $a$ is normally distributed with mean as the estimate of the SMA regression slope and standard deviation as the standard error (se) of the regression slope of $S_{\mathrm{w}}$ for all 3 solutes vs. $Q / w$ in reference streams only (see results). We use a channel width exponent $(b)$ based on a meta analysis of downstream (as opposed to at-a-station) hydraulic geometry of channels (Singh, 2003). Often these data are collected at bankfull discharge, but there is variation in discharge regime among specific studies such that these data are calculated from a wide range of $Q$ (Park, 1977). We use 38 estimates of worldwide rivers from Singh (2003); mean was 0.47 and standard deviation was 0.13 , and the distribution of $b$ included the exponent derived from streams in our data set (0.39). Hack's constant, $h$, is drawn from studies from 13 rivers; mean was 0.55 and standard deviation was 0.022 (Rigon et al., 1996). For $c$ we use data from 4 river networks with $c \sim 0.8$ (Galster, 2007); this value of $c$ is likely $<1$ because of unequal distribution of rainfall in the headwater areas of rivers (Galster, 2007), while the mean of $c$ was 0.83 and standard deviation was 0.057 . For $b, h$, and $c$, rather than assuming a distribution, we randomly drew values from the range of values collected from the literature; we evaluated $m 10000$ times, and used the median and 5\% and $95 \%$ quantiles to report variation on possible values. 
Table 1. Parameter estimates and statistics from standardized major axis regressions of $\log _{10}$ uptake length $\left(S_{\mathrm{W}}\right)$ vs. $\log _{10}$ specific discharge $(Q / w)$. CI is confidence interval, $n$ is sample size, $r^{2}$ is goodness of fit.

\begin{tabular}{llcrrrrr}
\hline Solute & Land use & Slope $(a)$ & $95 \%$ CI & Intercept & $95 \%$ CI & $n$ & $r^{2}$ \\
\hline \multirow{2}{*}{$\mathrm{NH}_{4}^{+}$} & reference & 1.01 & $0.90,1.14$ & 2.41 & $2.32,2.48$ & 111 & 0.57 \\
& altered & 1.20 & $0.94,1.54$ & 2.65 & $2.52,2.79$ & 35 & 0.49 \\
\hline \multirow{2}{*}{$\mathrm{NO}_{3}^{-}$} & reference & 1.19 & $1.01,1.4$ & 2.92 & $2.79,3.06$ & 133 & 0.13 \\
& altered & 1.12 & $0.90,1.39$ & 3.34 & $3.15,3.53$ & 65 & 0.24 \\
\hline \multirow{2}{*}{$\mathrm{SRP}$} & reference & 1.35 & $1.18,1.53$ & 2.55 & $2.46,2.66$ & 102 & 0.57 \\
& altered & 1.13 & $0.63,2.03$ & 2.67 & $2.31,3.03$ & 12 & 0.15 \\
\hline
\end{tabular}
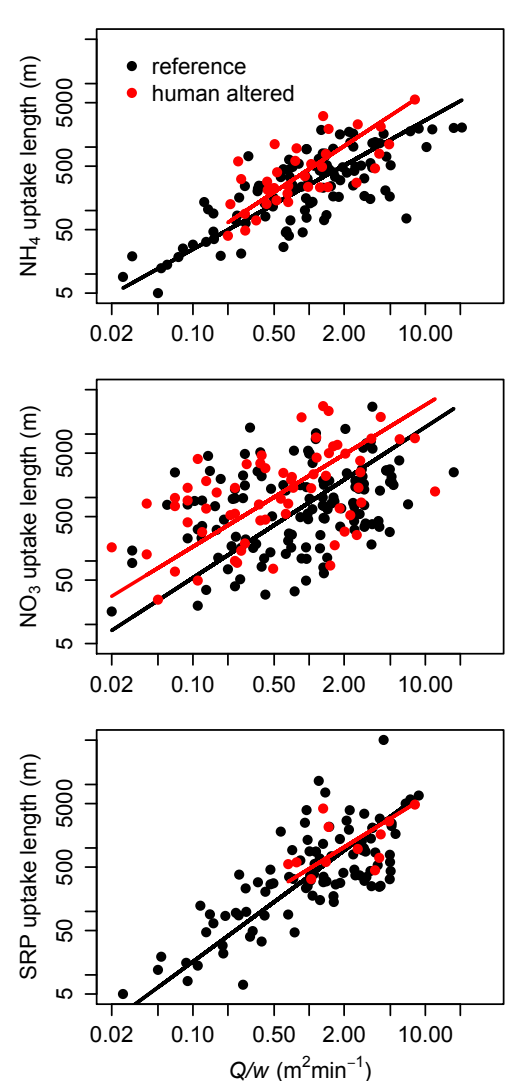

Fig. 1. Nutrient uptake length scaled isometrically for ammonium $\left(S_{\mathrm{W}-\mathrm{NH}_{4}}\right)$, and allometrically for nitrate $\left(S_{\mathrm{W}-\mathrm{NO}_{3}}\right)$ and soluble reactive phosphorus $\left(S_{\mathrm{W}-\mathrm{SRP}}\right)$ as a function of stream-specific discharge $(Q / w)$. Points are data from individual streams and lines are standardized major axis regression lines fit through the data. Red points are streams with substantial human land use alteration in the watershed. Black points are reference streams. Parameters for regression equations are in Table 1.

\section{Results}

Ammonium uptake scaled isometrically with specific discharge $(Q / w)$. The relationship had an SMA slope of 1.01 and a confidence interval including 1 (Fig. 1, Table 1), demonstrating that as $Q / w$ increased, $\mathrm{NH}_{4}^{+}$uptake in- creased at the same rate. Slopes of $\mathrm{NH}_{4}^{+}$uptake vs. $Q / w$ using data from human-altered streams were not different than those for reference streams, but the intercept was higher $(p=0.0014)$, suggesting that for equivalent $Q / w$, human-altered streams had longer uptake length, i.e., nutrients traveled farther prior to uptake. Constraining the reference streams to the same size as altered streams resulted in the same finding, i.e., significantly higher intercepts. Including concentration and $Q / w$ in a multiple linear regression model showed that concentration increased $S_{\mathrm{w}}$ (Table 2).

Nitrate uptake length scaled with $Q / w$ with a slope $=1.19$, and the relationship included more variation than for $\mathrm{NH}_{4}^{+}$(Fig. 1, Table 1). In contrast, the confidence interval for the slope of the relationship did not include 1, suggesting that as $Q / w$ increased, streams were less retentive of $\mathrm{NO}_{3}^{-}$. Similar to the results for $\mathrm{NH}_{4}^{+}$, the slopes did not differ between reference and human-altered streams $(p=0.65)$, but the intercept for human-altered streams was higher $(p=0.0001)$ by 0.42 , suggesting that uptake lengths averaged $2.6\left(10^{0.42}\right)$ times longer in human-altered streams. Adding concentration to a multiple regression model with $Q / w$ increased the goodness of fit, showing that much of the unexplained variation in $\mathrm{NO}_{3}^{-} S_{\mathrm{w}}$ vs. $Q / w$ was from variation in concentration (Table 2 ). Soluble reactive phosphorus scaled with $Q / w$ with a slope of 1.35 , which like that for $\mathrm{NO}_{3}^{-}$was $>1$, but the relationship for SRP had much less variation and smaller confidence intervals compared to the other two solutes (Fig. 1, Table 1). For SRP, human-altered streams shared the same regression slope $(p=0.55)$ and intercept $(p=0.72)$ as reference streams; however, there were fewer data for SRP uptake in human-altered streams compared to those for inorganic $\mathrm{N}$ species (Table 1). For SRP uptake, there were few reference streams in the same size range as the streams with altered land use, which limited our analysis; nevertheless, using similarly sized streams resulted in the same outcome of no differences in slope or intercept. Concentration had at best a small effect on variation in SRP uptake, with a parameter confidence interval including 0 (Table 2).

Many streams had uptake length estimates for $>1$ solute, either for both $\mathrm{NH}_{4}^{+}$and SRP, or both $\mathrm{NO}_{3}^{-}$and SRP; 
Table 2. Parameter estimates and statistics from multiple linear regression of $\log _{10}$ solute uptake length $(m)$ vs. $\log _{10}$ specific discharge $(Q / w), \log _{10}$ solute concentration. Confidence intervals (CI) are $t$-based CI from regression standard error. Number of cases is $n$ and goodness of fit is $R^{2}$. $p$ values for all parameters are $<0.00001$ except for SRP concentration, which has $p=0.054$. Because of different line-fitting methods, parameters for multiple linear regression are not the same as for standardized major axis regression.

\begin{tabular}{llcccc}
\hline Solute & Variables & Estimate & $95 \% \mathrm{CI}$ & $n$ & $R^{2}$ \\
\hline $\mathrm{NH}_{4}^{+}$ & $Q / w$ & 0.68 & $2.00,2.24$ & 144 & 0.64 \\
& concentration & 0.36 & $0.57,0.79$ & & \\
& intercept & 2.12 & $0.24,0.47$ & & \\
\hline $\mathrm{NO}_{3}^{-}$ & $Q / w$ & 0.45 & $0.31,0.59$ & 184 & 0.32 \\
& concentration & 0.30 & $0.21,0.38$ & & \\
& intercept & 2.44 & $2.27,2.61$ & & \\
\hline $\mathrm{SRP}$ & $Q / w$ & 1.01 & $0.84,1.17$ & 112 & 0.57 \\
& concentration & 0.13 & $0.63,2.03$ & & \\
& intercept & 2.46 & $0.00,0.27$ & & \\
\hline
\end{tabular}

therefore we compared the ratio of inorganic $\mathrm{N}$ uptake length to SRP uptake lengths across a range of stream sizes. The ratio of $\log _{10} \mathrm{NH}_{4}^{+}$to SRP uptake length declined with increasing $\log _{10}(Q / w)$, indicating that as $Q / w$ increased, the demand for $\mathrm{NH}_{4}^{+}$relative to SRP increased (Fig. 2). Similarly, $\mathrm{NO}_{3}^{-}$showed the same pattern, but the ratio of $\log _{10}$ $\mathrm{NO}_{3}^{-}$to SRP declined with increasing $\log _{10}(Q / w)$ (Fig. 2).

The scaling exponent between distance from the headwaters (length) vs. nutrient uptake length (Eq. 10) depended upon solute type, but was generally near or lower than 1 (Fig. 3). For $\mathrm{NH}_{4}^{+}$, the median $m_{\mathrm{NH}_{4}}=0.80$ with a 5-95\% confidence range of $0.47-1.19$ (Fig. 3). A median parameter estimate of $0.80\left(S_{\mathrm{w}} \propto L^{0.80}\right)$ suggested that uptake length of $\mathrm{NH}_{4}^{+}$will increase more slowly as one moves from the headwaters downstream (Fig. 4). Nitrate and SRP scaling exponents were larger (median of $m_{\mathrm{NO}_{3}}=0.93,5-95 \%$ confidence range of 0.58 to 1.39 ; median of $m_{\mathrm{SRP}}=1.06,5-95 \%$ confidence range of 0.66 to 1.59 ) (Fig. 3). These values suggest that uptake lengths of $\mathrm{NO}_{3}^{-}$and SRP will increase at the same rate as downstream distance from the headwaters (Fig. 4). Estimates of $m$ within any one solute included a broad range of variation (Fig. 3). Variation in the hydraulic geometry exponent, $b$ (scaling width as a function of $Q$ ), drove much of the variation in $m$ because $b$ had the highest relative variation among the variables in Eq. (10).

\section{Discussion}

\subsection{Differential uptake of $\mathrm{NH}_{4}^{+}, \mathrm{NO}_{3}^{-}$, and $\mathrm{SRP}$}

We have provided a scaling framework to examine how an ecosystem process such as nutrient uptake can vary as a func-
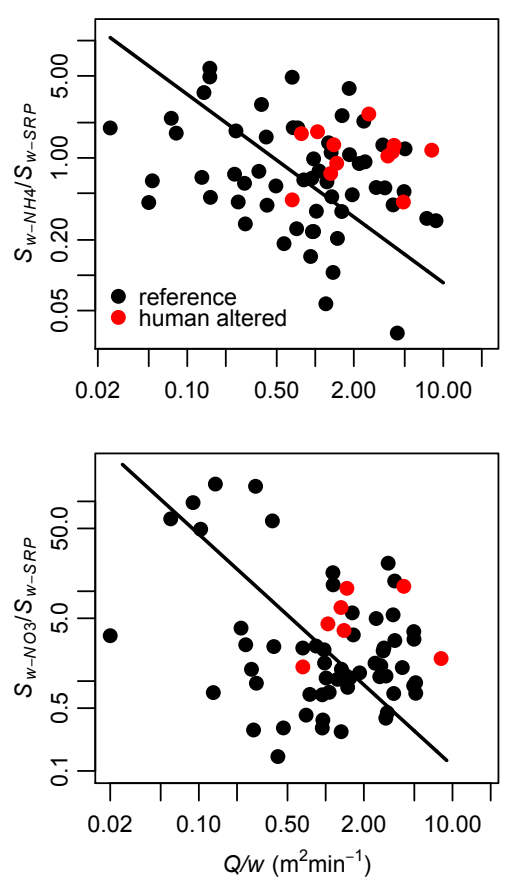

Fig. 2. Ratio of ammonium uptake length $\left(S_{\mathrm{W}-\mathrm{NH}_{4}}\right)$ and nitrate uptake length $\left(S_{\mathrm{W}-\mathrm{NO}_{3}}\right)$ to soluble reactive phosphorus uptake length $\left(S_{\mathrm{W}-\mathrm{SRP}}\right)$, declined with specific discharge $(Q / w)$ where measured in the same stream. Lines are ordinary least squares for only the reference streams, $\log _{10}\left(S_{\mathrm{W}-\mathrm{NH}_{4}} / S_{\mathrm{W}-\mathrm{SRP}}\right)$ $=-0.25 \log _{10}(Q / w)-0.20\left(n=57, p=0.017, r^{2}=0.082\right)$ and $\log _{10}\left(S_{\mathrm{W}-\mathrm{NO}_{3}} / S_{\mathrm{W}-\mathrm{SRP}}\right)=-0.43 \log _{10}(Q / w)+0.34 \quad(n=57$, $\left.p=0.011, r^{2}=0.094\right)$.

tion of stream size (measured as $Q / w$ ) and as distance increases downstream from the headwaters. Nutrient uptake lengths scaled differently with specific discharge such that $\mathrm{NH}_{4}^{+}$uptake length scaled isometrically (i.e., $a=1$ ) with $Q / w$, while uptake lengths for $\mathrm{NO}_{3}^{-}$and SRP scaled allometrically $(a>1)$, indicating a declining demand $\left(v_{\mathrm{f}}\right)$ with increasing $Q / w$. A scaling exponent of 1 is the same as the assumption of constant $v_{\mathrm{f}}$ across a range of stream sizes (Wollheim et al., 2006), and a constant $v_{\mathrm{f}}$ implies that larger rivers could strongly contribute to nutrient uptake within a river network (Wollheim et al., 2006). For example, empirical data for the Ipswich, MA watershed supported this model (Wollheim et al., 2008). Other ecosystem processes can also vary in a downstream direction. For example, nutrient export from forested watersheds can depend on the size of the watershed (Likens and Buso, 2006), and degree of allochthony may depend on river size (Vannote et al., 1980). Using a scaling framework provides a mechanism for quantifying how uptake length varies with specific discharge $(Q / w)$, and allows us to link nutrient cycling with stream geomorphology along a stream network. In addition, because nutrient uptake experiments have been carried out in many streams, we could provide a constrained estimate of the scaling exponents. 


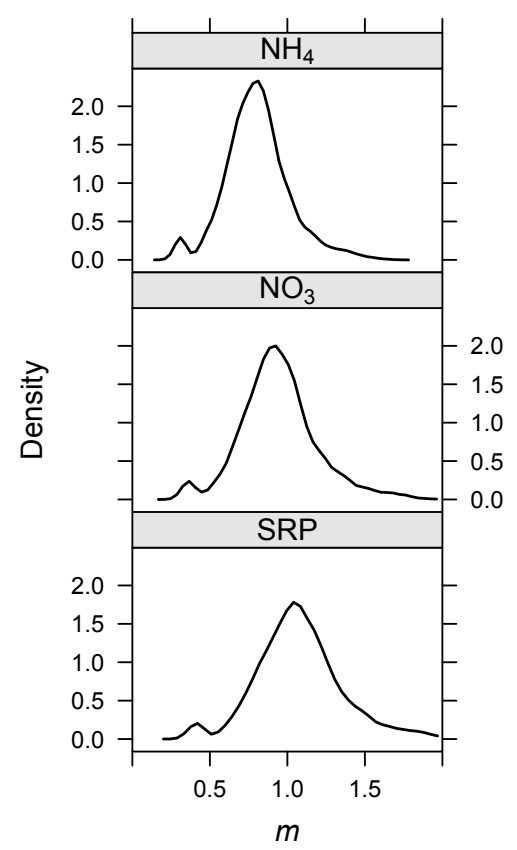

Fig. 3. Distribution of the scaling exponent, $m$, which relates uptake length of the 3 nutrients with distance from the headwaters. Lines are kernel densities based on a distribution of 10000 estimates of $m$ given uncertainty in parameters used to derive $m$ (Eq. 9, in text).

Because streams and rivers are characterized by the unidirectional flow of water, the relationship between $Q / w$ and relative inorganic $\mathrm{N}$ and $\mathrm{P}$ demand could be a result of upstream processing (Vannote et al., 1980), which could alter the stoichiometry of nutrients transported downstream (Schade et al., 2005). Additionally, attributes of stream morphology may directly affect nutrient cycling at a local scale, e.g., increased light availability in a larger (i.e., wider) stream may increase metabolic demand (e.g., algal primary production) for $\mathrm{N}$ (Hall et al., 2009b). Nevertheless, the cycling of $\mathrm{NH}_{4}^{+}, \mathrm{NO}_{3}^{-}$, and SRP must be partially decoupled; different processes drive the uptake of individual solutes as reflected in the differential scaling of $\mathrm{NH}_{4}^{+} \mathrm{NO}_{3}^{-}$, and SRP uptake length with stream size (Fig. 4). Two examples of this solute-specific scaling include (1) the abiotic sorption of SRP to particles not seen in "leaky" solutes like $\mathrm{NO}_{3}^{-}$, and (2) the gaseous loss of $\mathrm{NO}_{3}^{-}$via microbially-mediated denitrification that would not directly influence $\mathrm{NH}_{4}^{+}$.

The dynamics of abiotic sorption and desorption to/from fine particles in the water column and benthos may influence SRP uptake (Meyer, 1979). Despite the role of these abiotic factors, biota can quickly assimilate phosphorus, as shown from ${ }^{32} \mathrm{P}_{-} \mathrm{PO}_{4}$ tracer studies (Newbold et al., 1983). Given that sorption/desorption with mineral particles can control SRP concentrations (Froelich, 1988), changes in mineral characteristics and/or the degree of $\mathrm{P}$ sorption may drive the pattern of reduced demand for SRP as stream size increases, and this effect may be more pronounced in streams with

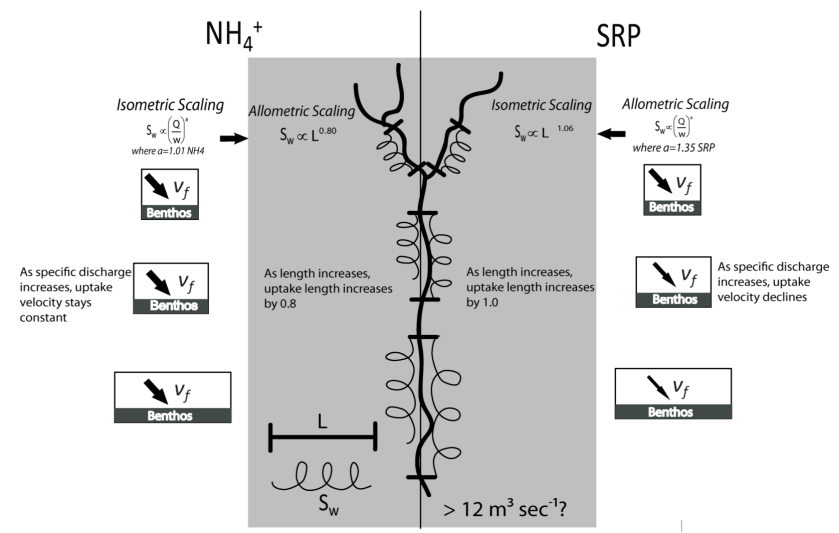

Fig. 4. Conceptual model demonstrates the relationships between scaling of uptake length $\left(S_{\mathrm{W}}\right)$ with stream size (measured as specific discharge, $Q / w)$ and stream length $(L)$ for ammonium $\left(\mathrm{NH}_{4}^{+}\right)$ and soluble reactive phosphorus (SRP). $v_{\mathrm{f}}$ is uptake velocity, the demand for nutrients relative to concentration.

higher suspended sediment loads. It has been suggested that increased equilibrium SRP concentrations would increase SRP uptake lengths given constant biological demand (Mulholland et al., 1990). Although $\mathrm{NH}_{4}^{+}$can also sorb to mineral surfaces, empirical studies show a consistent positive relationship between uptake velocity and stream biology measured as reach-scale metabolism (Hall and Tank, 2003; Newbold et al., 2006), suggesting that biological demand controls variation in $\mathrm{NH}_{4}^{+}$uptake.

Despite similar scaling exponents, the processes regulating $\mathrm{NO}_{3}^{-}$differed greatly from those of SRP. Isotopic tracer experiments have shown that most $\mathrm{NO}_{3}^{-}$uptake is assimilatory and is coupled to rates of GPP (Hall et al., 2009b), although varying proportions of $\mathrm{NO}_{3}^{-}$can be permanently lost from streams via denitrification (Alexander et al., 2000; Mulholland et al., 2008). If some fraction of $\mathrm{N}$ load is permanently lost from a stream via denitrification, then $\mathrm{NH}_{4}^{+}$ and $\mathrm{NO}_{3}^{-}$may have higher demand relative to SRP in large streams. We see this pattern for $\mathrm{NH}_{4}^{+}$, but not for $\mathrm{NO}_{3}^{-}$, and the scaling exponent of $\mathrm{NO}_{3}^{-}$uptake length vs. $Q / w$ was similar to that of SRP, showing no difference in demand with increasing $Q / w$.

\subsection{Effect of nutrient concentration on scaling}

Human alteration of streams (e.g., conversion to urban or agricultural land use) influenced the scaling of both $\mathrm{NH}_{4}^{+}$ and $\mathrm{NO}_{3}^{-}$, not by changing the slope of the relationship, but by increasing the value of the $y$ intercept. Thus humanaltered streams have proportionally longer uptake lengths, but similar scaling relationships with specific discharge. These results are consistent with research, showing that streams in human-altered landscapes export more nutrients (Royer et al., 2006); however, the relationship is not always straightforward. In a study of 69 streams, the effect of human 
land use was to concurrently increase $\mathrm{NO}_{3}^{-} S_{\mathrm{w}}$ due to high $\mathrm{NO}_{3}^{-}$concentrations, while simultaneously shortening $S_{\mathrm{w}}$ via augmented rates of photosynthesis (Hall et al., 2009b). However, when we used all 198 of the streams in this data set, we showed a consistent pattern of longer $\mathrm{NO}_{3}^{-}$uptake lengths in human-altered streams.

There were large differences in variability among the solute scaling relationships, with $\mathrm{NO}_{3}^{-}$varying more than the other 2 solutes. We suggest that this variability resulted from highly variable $\mathrm{NO}_{3}^{-}$concentrations, which can vary by $>10^{5}$, and that this variation in concentration strongly regulates $S_{\mathrm{w}}$ (Hall et al., 2009b). Linear models of $S_{\mathrm{w}}$ vs. $\mathrm{NO}_{3}^{-}$concentration and $Q / w$ had higher goodness of fit than those for $Q / w$ alone, showing that concentration explained some of the variation in $\mathrm{NO}_{3}^{-} S_{\mathrm{w}}$. Concentration also explained some variation in $\mathrm{NH}_{4}^{+}$uptake, but with less of an increase in goodness of fit relative to that for $\mathrm{NO}_{3}^{-}$. Finally, SRP concentration explained little additional variation and the confidence interval of the parameter included 0 , suggesting that variation in ambient concentration was a relatively unimportant control on SRP $S_{\mathrm{w}}$.

\section{Scaling uptake length with stream distance downstream from headwaters}

For all 3 solutes, the exponent, $m$, for scaling uptake length with distance, $L$, from headwaters, was near $1(0.80-1.06$, Fig. 3), but less than the respective exponent, $a$, for scaling with stream size $(Q / w)$. Thus, $S_{\mathrm{w}}$ for $\mathrm{NH}_{4}^{+}$scaled allometrically with $L(m=0.80)$ while scaling isometrically with $(Q / w)(a=1)$. In contrast, $S_{\mathrm{w}}$ for nitrate and SRP scaled isometrically with $L$ ( $m=0.93$ and 1.06, respectively) while scaling allometrically with $Q / w(a=1.19$ and 1.35 , respectively) (Fig. 4). For the allometric scaling, the downstream increase in $S_{\mathrm{w}}$ is less than proportional to $L$, while for the isometric scaling, $S_{\mathrm{w}}$ increases linearly with $L$.

Much of the variation in the scaling exponent, $m$, was due to variation in the scaling exponent $b$ for downstream hydraulic geometry. This exponent had a coefficient of variation of 0.27 , which was 3 times higher than for the other variables in Eq. (10). We emphasize that this variation in $m$ does not represent uncertainty in the average estimate of $b$, but rather absolute variation in the scaling of hydraulic geometry among watersheds. Thus, scaling predictions for a specific watershed should quantify the downstream hydraulic geometry of rivers in that particular watershed as first suggested by Wollheim et al. (2008).

Our simple model has shown that uptake length increases in the downstream direction either proportionately (isometrically) or less-than-proportionately (allometrically) to distance from the headwaters. Uptake length is the ratio of the downstream flux of a nutrient to its uptake per unit distance (Newbold et al., 1981), raising the question of whether a larger stream takes up a greater or lesser fraction of its down- stream flux than a smaller stream. Ensign and Doyle (2006) addressed this question by calculating the number of uptake lengths in a stream of a given order as:

$\rho_{i}=l_{i} / S_{\mathrm{W} i}$,

where $l_{i}$ is the mean channel length of streams of order $i$, and $S_{\mathrm{W} i}$ is the respective uptake length. Using uptake length as a surrogate for spiraling length, $\rho_{i}$ can be interpreted as the number of nutrient cycles completed within the $i$-order segment. Based on a meta-analysis of empirically measured uptake lengths, Ensign and Doyle found $\rho_{i}$ to be more or less uniform over orders 1-4, with variable results (based on relatively few measurements) for the 5 th order. We show here that the uniformity of $\rho_{i}$ over stream order is predicted by isometric scaling of uptake length of $\mathrm{NO}_{3}^{-}$and SRP with distance from the headwaters.

Because streams increase their size within an order, we can consider the increase continuously:

$\mathrm{d} \rho=\frac{\mathrm{d} L}{S_{\mathrm{W}}(L)}$,

where $S_{\mathrm{W}}(L)$ is uptake length changing as a function of stream length. For isometric scaling, $S_{\mathrm{W}}(L)=\alpha L$, where $\alpha$ is a constant. Substituting into Eq. (2) yields

$\mathrm{d} \rho=\frac{\mathrm{d} L}{\alpha L}$.

To obtain the number of cycles in a reach of order $i$, we integrate over the mainstem length from the end of order $i-1$ to the end of order $i$ :

$\rho_{i}=\int_{L_{i-1}}^{L_{i}} \mathrm{~d} \rho=\frac{1}{\alpha} \int_{L_{i-1}}^{L_{i}} \frac{\mathrm{d} L}{L}=\frac{1}{\alpha} \ln \left(\frac{L_{i}}{L_{i-1}}\right)$

If we take $L_{i-1}$ as the average length of streams of order $i-1$ within the basin, then the ratio $L_{i} / L_{i-1}$ is Horton's (Horton, 1945) length ratio, which he showed to be uniform across stream order. Thus, for isometric scaling, the number of cycles (or spirals), and hence the nutrient uptake as a fraction (or multiple) of the downstream flux, is expected to be the same for large streams as for small streams, in agreement with Ensign and Doyle's (2006) empirical result. Note that although the length ratio is expressed using full mainstem lengths (as did Horton originally), the result applies to a Strahler-order segment (Strahler, 1952), i.e., measured from the confluence of two lower (Strahler) order segments. Measured across a drainage network, the two systems yield nearly identical length ratios (Scheidegger, 1968).

Although we showed how nutrient uptake scaled across a range of stream sizes, these scaling exponents should not be extrapolated to large rivers without further empirical data collection (Tank et al., 2008). Although our analysis included a range of streams that varied 30000 -fold in discharge, we still lack data from rivers. The largest stream in our analysis, Lower Kuparuk River, Alaska $\left(18 \mathrm{~m}^{3} \mathrm{~s}^{-1}\right)$ is about 100fold smaller than the median discharge of river basins in 
North America $\left(1930 \mathrm{~m}^{3} \mathrm{~s}^{-1}\right.$; Allan and Benke, 2005). Median stream discharge in our data set was $0.035 \mathrm{~m}^{3} \mathrm{~s}^{-1}$, reflecting the emphasis and historical focus that ecologists have placed on small headwater streams, both because they are important with regard to their potential for nutrient uptake and transformation (Mulholland et al., 2008), and because it is far more tractable to experimentally measure nutrient uptake in small streams than large rivers (Tank et al., 2008). Given the empirical data available, our scaling approach assumes that rivers will act like large streams, yet we suggest that scaling relationships for small streams will not necessarily hold for rivers because of the addition of potamoplankton to biological processes in rivers, higher sediment loads, larger floodplains, higher nutrient concentrations, and the influence of human-altered hydrology, e.g., dams. Thus, the processes that control nutrient uptake in streams, i.e., uptake dominated by benthic biofilms (Tank et al., 2000), or hyporheic storage (Hall et al., 2009a), may not apply to rivers that may exhibit fundamentally different patterns and drivers of nutrient cycling. Data for reach-scale nutrient cycling rates in rivers await further investigation.

\section{Supplementary material related to this article is available online at http://www.biogeosciences.net/10/ 7323/2013/bg-10-7323-2013-supplement.zip.}

Acknowledgements. Thanks to B. Koch, L. Tronstad, and A. Flecker for providing additional unpublished data on $\mathrm{NH}_{4}^{+}$ uptake. Discussions with C. Martinez del Rio and C. Legleiter and comments from an anonymous reviewer greatly improved this paper. This research was supported by the NSF grants DEB 01-11410, DEB 01-32983, EAR 04-05934, and DEB 09-21598.

Edited by: T. J. Battin

\section{References}

Alexander, R. B., Smith, R. A., and Schwarz, G. E.: Effect of stream channel size on the delivery of nitrogen to the Gulf of Mexico, Nature, 403, 758-761, doi:10.1038/35001562, 2000.

Allan, J. D. and Benke, A. C.: Overview and prospects, in: Rivers of North America, edited by: Benke, A. C. and Cushing, C. E., 1087-1103, 2005.

Arp, C. D. and Baker, M. A.: Discontinuities in stream nutrient uptake below lakes in mountain drainage networks, Limnol. Oceanogr., 52, 1978-1990, 2007.

Bormann, F. H. and Likens, G. E.: Nutrient cycling, Science, 155, 424-429, doi:10.1126/science.155.3761.424, 1967.

Cross, W. F., Benstead, J. P., Frost, P. C., and Thomas, S. A.: Ecological stoichiometry in freshwater benthic systems: recent progress and perspectives, Freshwater Biol., 50, 1895-1912, 2005.

Dodds, P. S. and Rothman, D. H.: Scaling, universality, and geomorphology, Annu. Rev. Earth Pl. Sc., 28, 571-610, 2000.
Ensign, S. H. and Doyle, M. W.: Nutrient spiraling in streams and river networks, J. Geophys. Res., 111, G04009, doi:10.1029/2005JG000114, 2006.

Froelich, P.: Kinetic control of dissolved phosphate in natural rivers and estuaries - a primer on the phosphate buffer mechanism, Limnol. Oceanogr., 33, 649-668, 1988.

Galster, J. C.: Natural and anthropogenic influences on the scaling of discharge with drainage area for multiple watersheds, Geosphere, 3, 260-271, 2007.

Hall, R. O. and Tank, J. L.: Ecosystem metabolism controls nitrogen uptake in streams in Grand Teton National Park, Wyoming, Limnol. Oceanogr., 48, 1120-1128, 2003.

Hall, R. O., Baker, M. A., Arp, C. D., and Koch, B. J.: Hydrologic control of nitrogen removal, storage, and export in a mountain stream, Limnol. Oceanogr., 54, 2128-2142, 2009a.

Hall, R. O., Tank, J. L., Sobota, D. J., Mulholland, P. J., O’Brien, J. M., Dodds, W. K., Webster, J. R., Valett, H. M., Poole, G. C., Peterson, B. J., Meyer, J. L., McDowell, W. H., Johnson, S. L., Hamilton, S. K., Grimm, N. B., Gregory, S. V., Dahm, C. N., Cooper, L. W., Ashkenas, L. R., Thomas, S. M., Sheibly, R. W., Potter, J. D., Niederlehner, B. W., Johnson, L. T., Helton, A. M., Crenshaw, C. M., Burgin, A. J., Bernot, M. J., Beaulieu, J. J., and Arango, C. P.: Nitrate removal in stream ecosystems measured by $15 \mathrm{~N}$ addition experiments: total uptake, Limnol. Oceanogr., 54, 653-665, 2009b.

Horton, R. E.: Erosional development of streams and their drainage basins; hydrophysical approach to quantitative morphology, Geol. Soc. Am. Bull., 56, 275-370, 1945.

Kratz, T. K., Webster, K. E., Bowser, C. J., Magnuson, J. J., and Benson, B. J.: The influence of landscape position on lakes in northern Wisconsin, Freshwater Biol., 37, 209-217, 1997.

Leopold, L. B. and Maddock, T.: The hydraulic geometry of stream channels and some physiographic implications, USGS Professional Paper 252, Reston, VA, 1953.

Likens, G. E. and Buso, D. C.: Variation in streamwater chemistry throughout the Hubbard Brook valley, Biogeochemistry, 78, 130, doi:10.1007/s10533-005-2024-2, 2006.

Meyer, J.: Role of sediments and bryophytes in phosphorus dynamics in a headwater stream ecosystem, Limnol. Oceanogr., 24, 365-375, 1979.

Mulholland, P. J., Steinman, A. D., and Elwood, J. W.: Measurement of phosphorus uptake length in streams - comparison of radiotracer and stable $\mathrm{PO}_{4}$ releases, Can. J. Fish. Aquat. Sci., 47, 2351-2357, 1990.

Mulholland, P. J., Helton, A. M., Poole, G. C., Hall, R. O., Hamilton, S. K., Peterson, B. J., Tank, J. L., Ashkenas, L. R., Cooper, L. W., Dahm, C. N., Dodds, W. K., Findlay, S. E. G., Gregory, S. V., Grimm, N. B., Johnson, S. L., McDowell, W. H., Meyer, J. L., Valett, H. M., Webster, J. R., Arango, C. P., Beaulieu, J. J., Bernot, M. J., Burgin, A. J., Crenshaw, C. L., Johnson, L. T., Niederlehner, B. R., O’Brien, J. M., Potter, J. D., Sheibley, R. W., Sobota, D. J., and Thomas, S. M.: Stream denitrification across biomes and its response to anthropogenic nitrate loading, Nature, 452, 202-205, doi:10.1038/nature06686, 2008.

Newbold, J. D., Elwood, J. W., O’Neill, R. V., and Van Winkle, W.: Measuring nutrient spiralling in streams, Can. J. Fish. Aquat. Sci., 38, 860-863, 1981. 
Newbold, J. D., Elwood, J. W., O’Neill, R. V., and Sheldon, A. L.: Phosphorus dynamics in a woodland stream ecosystem - a study of nutrient spiralling, Ecology, 64, 1249-1265, 1983.

Newbold, J. D., Bott, T. L., Kaplan, L. A., Dow, C. L., Jackson, J. K., Aufdenkampe, A. K., Martin, L. A., Van Horn, D. J., and de Long, A. A.: Uptake of nutrients and organic C in streams in New York City drinking-water-supply watersheds, J. N. Am. Benthol. Soc., 25, 998-1017, 2006.

O'Neill, R. V.: Is it time to bury the ecosystem concept? (With full military honors of course!), Ecology, 82, 3275-3284, 2001.

Park, C. C.: World-wide variations in hydraulic geometry exponents of stream channels: an analysis and some observations, J. Hydrol., 33, 133-146, 1977.

Post, D. M., Doyle, M. W., Sabo, J. L., and Finlay, J. C.: The problem of boundaries in defining ecosystems: a potential landmine for uniting geomorphology and ecology, Geomorphology, 89, 111-126, 2007.

R Development Core Team: R: A language and environment for statistical computing, R Foundation for Statistical Computing, Vienna, available at: http://www.R-project.org/ (last access: 6 July 2011), 2011.

Rigon, R., Rodriguez-Iturbe, I., Maritan, A., Giacometti, A., Tarboton, D. G., and Rinaldo, A.: On Hack's law, Water Resour. Res., 32, 3367-3374, 1996.

Royer, T. V., David, M. B., and Gentry, L. E.: Timing of riverine export of nitrate and phosphorus from agricultural watersheds in Illinois: implications for reducing nutrient loading to the Mississippi River, Environ. Sci. Technol, 40, 4126-4131, doi:10.1021/es052573n, 2006.

Schade, J. D., Espeleta, J. F., Klausmeier, C. A., McGroddy, M. E., Thomas, S. A., and Zhang, L. X.: A conceptual framework for ecosystem stoichiometry: balancing resource supply and demand, Oikos, 109, 40-51, 2005.

Scheidegger, A. E.: Horton's laws of stream lengths and drainage areas, Water Resour. Res., 4, 1015-1021, 1968.

Singh, V. P.: On the theories of hydraulic geometry, Int. J. Sediment Res., 18, 196-218, 2003.
Soranno, P. A., Webster, K. E., Riera, J. L., Kratz, T. K., Baron, J. S., Bukaveckas, P. A., Kling, G. W., White, D. S., Caine, N., and Lathrop, R. C.: Spatial variation among lakes within landscapes: ecological organization along lake chains, Ecosystems, 2, 395410, 1999.

Strahler, A. N.: Hypsometric (area-altitude) analysis of erosional topography, Geol. Soc. Am. Bull., 63, 1117-1142, 1952.

Stream Solute Workshop: Concepts and methods for assessing solute dynamics in stream ecosystems, J. N. Am. Benthol. Soc., 9, 95-119, 1990.

Tank, J. L., Meyer, J. L., Sanzone, D. M., Mulholland, P. J., Webster, J. R., Peterson, B. J., Wollheim, W. M., and Leonard, N. E.: Analysis of nitrogen cycling in a forest stream during autumn using a 15N-tracer addition, Limnol. Oceanogr., 45, 1013-1029, 2000.

Tank, J. L., Rosi-Marshall, E. J., Baker, M. A., and Hall, R. O.: Are rivers just big streams? A pulse method to quantify nitrogen demand in a large river, Ecology, 89, 2935-2945, 2008.

Vannote, R., Minshall, G., Cummins, K., Sedell, J., and Cushing, C.: The river continuum concept, Can. J. Fish. Aquat. Sci., 37, 130-137, 1980.

Warton, D. I., Wright, I. J., Falster, D. S., and Westoby, M.: Bivariate line-fitting methods for allometry, Biol. Rev., 81, 259-291, doi:10.1017/S1464793106007007, 2006.

Webster, J. and Patten, B.: Effects of watershed perturbation on stream potassium and calcium dynamics, Ecol. Monogr., 49, 51$72,1979$.

Wickham, H.: The split-apply-combine strategy for data analysis, J. Stat. Softw., 40, 1-29, 2011.

Wollheim, W. M., Vörösmarty, C. J., Peterson, B. J., Seitzinger, S. P., and Hopkinson, C. S.: Relationship between river size and nutrient removal, Geophys. Res. Lett., 33, L06410, doi:10.1029/2006GL025845, 2006.

Wollheim, W. M., Peterson, B. J., Thomas, S. M., Hopkinson, C. S., and Vörösmarty, C. J.: Dynamics of N removal over annual time periods in a suburban river network, J. Geophys. Res., 113, G03038, doi:10.1029/2007JG000660, 2008. 